\title{
Risk of Guillain-Barré syndrome after vaccination against human papillomavirus: a systematic review and meta-analysis, 1 January 2000 to 4 April 2020
}

T Sonia Boender ${ }^{1,2,3}$, Barbara Bartmeyer ${ }^{1}$, Louise Coole ${ }^{3,4}$, Ole Wichmann ${ }^{1}$, Thomas Harder ${ }^{1}$

1. Department of Infectious Disease Epidemiology, Robert Koch Institute, Berlin, Germany

2. Postgraduate Training for Applied Epidemiology (PAE), Robert Koch Institute, Berlin, Germany

3. European Programme for Intervention Epidemiology Training (EPIET), European Centre for Disease Prevention and Control $(E C D C)$, Stockholm, Sweden

4. Field Service, UK Health Security Agency, Leeds, United Kingdom

\section{Correspondence: T Sonia Boender (BoenderS@rki.de)}

\section{Citation style for this article:}

Boender T Sonia, Bartmeyer Barbara, Coole Louise, Wichmann Ole, Harder Thomas. Risk of Guillain-Barré syndrome after vaccination against human

papillomavirus: a systematic review and meta-analysis, 1 January 2000 to 4 April 2020. Euro Surveill. 2022;27(4):pii=2001619. https://doi.org/10.2807/1560-7917. ES.2022.27.4.2001619

Background: Guillain-Barré syndrome (GBS) is a rare autoimmune disease that can follow viral infections and has in a few cases been linked to vaccinations. Pre-licensure clinical trials did not observe an association between human papillomavirus (HPV) vaccination and GBS, a post-marketing study from 2017 reported an increased relative risk. Aim: We assessed the risk of GBS after HPV vaccination through a systematic literature review and meta-analysis. Methods: We searched Embase, MEDLINE and Cochrane for studies reporting on the risk of GBS after HPV vaccination in individuals aged $\geq 9$ years, published between 1 January 2000 and 4 April 2020, excluding studies without a comparator group. Seven studies reporting relative effect sizes were pooled using random-effects meta-analysis. We assessed quality of evidence using the GRADE approach. Study protocol was registered (PROSPERO No. \#CRD42019123533). Results: Of 602 identified records, we included 25 studies. Based on over 10 million reports, cases of GBS were rare. In 22 studies no increased risk was observed, while in three studies a signal of increased risk of GBS after HPV vaccination was identified. Meta-analysis yielded a pooled random-effects ratio of 1.21 ( $95 \% \mathrm{Cl}: 0.60-2.43$ ); $\mathrm{I}^{2}=72 \%(95 \% \mathrm{Cl}: 36-88)$. This translates to a number needed to harm of one million to be vaccinated to generate one GBS case. Quality of evidence was very low. Conclusions: The absolute and relative risk of GBS after HPV vaccination is very low and lacks statistical significance. This is reassuring for the already implemented vaccination programmes and should be used in respective communication activities.

\section{Background}

More than 10 years after the licensure of the first human papillomavirus (HPV) vaccines, a growing body of evidence supports the large-scale implementation of HPV immunisation programmes. Clinical trials and postmarketing observational studies have shown consistent efficacy, effectiveness and safety of the available HPV vaccines: (i) the bivalent Cervarix, (targeting HPV types 16 and 18, GlaxoSmithKline Biologicals, Rixensart, Belgium); (ii) the 4-valent recombinant Gardasil (targeting HPV types $6,11,16$, and 18, MSD VACCINS, Lyon, France) and; (iii) the 9-valent Gardasil 9 (targeting HPV types $6,11,16,18,31,33,45,52$ and 58, MSD VACCINS) $[1,2]$. Vaccination against HPV reduces the prevalence and incidence of cervical intraepithelial neoplasia grade 2 or 3 or worse ( $\mathrm{CIN}_{2} / 3$ or worse) among girls and women and anogenital warts diagnoses among girls, women, boys and men [3]. Since 2007, HPV vaccination programmes have been implemented in most European countries, usually targeting females. In recent years, several countries have extended their recommendation to a gender-neutral programme [4]. Notably, herd effects have been measured in countries with high HPV vaccination coverage $[3,5]$.

The future public health impact of HPV vaccination on HPV-associated disease will rely on the vaccination coverage achieved. While the expansion of vaccination programmes is encouraging and uptake is increasing, overall HPV vaccination rates remain low and below national targets in a number of countries $[6,7]$. Suboptimal vaccination coverage is often driven by vaccine hesitancy, which in turn is often related to public debates and fear of vaccine-induced side effects $[8,9]$. 


\section{FIGURE 1}

PRISMA flow diagram of studies that were screened to identify the risk of Guillain-Barré syndrome after vaccination against human papillomavirus, 1 January 2000-4 April $2020(\mathrm{n}=602)^{\mathrm{a}}$

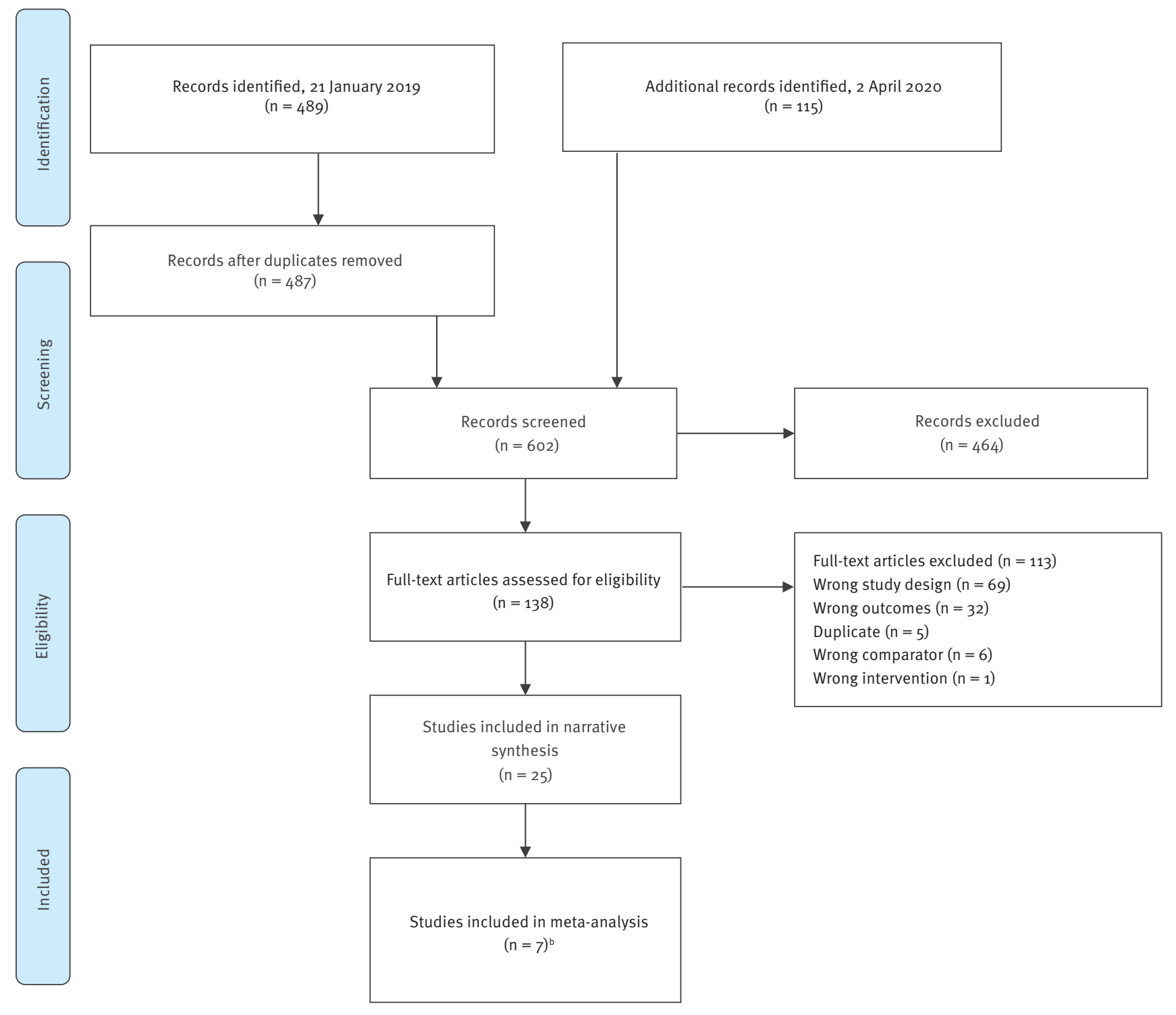

PRISMA: Preferred Reporting Items for Systematic Reviews and Meta-Analyses reporting guideline.

a The full search strategy and list of the excluded full-text papers can be found in the Supplement.

b Two studies published findings with a large overlap in data based on the VAERS dataset $[34,35]$ with similar findings. The effect estimate by Geier et al. 2017 [35] was used in the primary analyses and Geier et al. 2015 [34] estimate in the sensitivity analysis. Therefore, the results of the meta-analysis show findings of six studies.

Among the possible risks associated with vaccination, Guillain-Barré syndrome (GBS) is one of the most serious. Guillain-Barré syndrome is a rare autoimmune disease where the body's immune system damages nerve cells, causing muscle weakness and, in some cases, paralysis. Most people recover, however, some have lasting long-term weakness and GBS can be fatal. It occurs with a frequency of less than one case per 100,000 person-years in the age group relevant for HPV vaccination, i.e. those aged $10-19$ years $[10,11]$.
The causes of GBS are not yet fully understood, however, it often occurs after viral or bacterial infections and, in rare cases, after vaccination [12].

While pre-licensure clinical trials showed no association between HPV vaccination and subsequent occurrence of GBS, a French study from 2017 reported a more than threefold increased relative risk [13]. No evidence of an association between HPV vaccination and any autoimmune disorder has been found so far [9]. To the 
best of our knowledge, there is no systematic literature review investigating the potential association between the HPV vaccination and GBS specifically. We assessed the available evidence on the risk of GBS after HPV vaccination by including both randomised controlled trials (RCT) and post-marketing non-randomised studies.

\section{Methods}

We registered our systematic literature review protocol at the International Prospective Register for Systematic Reviews (PROSPERO) under the registration number CRD42019123533 [14]. We report our results according to the Preferred Reporting Items for Systematic Reviews and Meta-Analyses (PRISMA) reporting guideline [15]. We included all studies reporting on individuals aged 9 years and older (i.e. the licenced age) who have been vaccinated against HPV with one of these vaccines: the bivalent Cervarix; (ii) the 4 -valent recombinant Gardasil and; (iii) the 9-valent Gardasil 9. We included all possible vaccination schedules, including stopped schedules.

We did not restrict any study design, however, we excluded studies lacking a comparator group. and any type of control group would suffice, given the fact that there is one (e.g. placebo, no/other vaccination). We did not restrict our search based on language or geography.

The outcome of interest was GBS after HPV vaccination, as sub-defined by Brighton criteria [16] and all other non-Brighton criteria. According to the Brighton criteria, GBS includes acute inflammatory demyelinating polyradiculoneuropathy and acute motor axonal neuropathy. Other, non-Brighton criteria include Miller Fisher syndrome, which is a subtype of GBS characteristically consisting of the triad of ataxia, areflexia, ophthalmoplegia, acute motor and sensory axonal neuropathy and overlap syndromes between GBS and Miller Fisher syndrome.

We reviewed all literature reporting on the risk of occurrence of GBS after HPV vaccination, published between 1 January 2000 and 21 January 2019 and indexed in Embase, MEDLINE and the Cochrane Central Register of Controlled Trials. On 2 April 2020, we updated our search and included an additional search for publications in PubMed. We provide the full search strategy in the Supplement. Additionally, we used the snowballing approach to include additional studies by hand-searching the citation lists of included studies.

\section{Study selection and data collection}

We uploaded all records to Covidence, a screening and data extraction tool for systematic reviews. Two reviewers (TSB and $\mathrm{TH}$ ) independently included and excluded studies, using a stepwise approach based on title and abstract screening and a subsequent full-text screening.
Subsequently, one reviewer (TSB) extracted data from the included studies using a pre-defined data extraction sheet (the data extraction sheet is included in the Supplement). The second reviewer $(\mathrm{TH})$ revised the data extractions against the original papers to identify potential errors. In case of disagreement, a final decision was made by consensus between the reviewers.

From the included studies, we extracted: (i) information on the study set-up (design, location, study period and follow-up time in person-years, inclusion and exclusion criteria); (ii) study population, (sex; age; number of people included in total, and by vaccinated/control group); (iii) intervention (type of vaccine used); (iv) control group; (v) potential co-interventions and; (vi) outcome (GBS definition; source of outcome reporting; incidence in the HPV-vaccinated and control groups). When available, we also extracted the incidence rate (IR) and all reported measures of association, including the incidence rate ratio (IRR), relative risk (RR), odds ratio $(O R)$, hazard ratio $(H R)$ and potentially corrected confounding factors. Furthermore, we collected funding source and reported conflict of interest as risk of bias indicators.

\section{Assessment of risk of bias and quality of the body of evidence}

Two reviewers (TSB and TH) independently assessed included studies for risk of bias. For RCT we used the revised Cochrane Collaboration's tool (RoB 2.0) [17] and for non-randomised studies the Risk of Bias in Non-randomized Studies - of Interventions (ROBINS-I) tool was used [18]. The overall assessment of the quality of the body of evidence followed the Grading of Recommendations Assessment, Development, and Evaluation (GRADE) approach [19] in its most recent version adapted for use of ROBINS-I [20].

\section{Meta-analysis}

All relative effect measures were pooled into one relative effect measure (ratio). Between-study heterogeneity in random-effects meta-analysis is reported through $\mathrm{I}^{2}$. Meta-analyses were conducted using the meta package in $R$ version 3.6.3 ( $R$ Foundation for Statistical Computing, Vienna, Austria).

Pre-specified subgroup analyses were planned to explore the potential effect of study design, vaccine type (i.e. bivalent vaccine, 4-valent recombinant vaccine and 9-valent vaccine) and GBS case definition (Brighton vs non-Brighton) on the pooled effect estimate. When multiple studies were reporting on the same data source but with different subgroups of reporting timeframes, the most recent and/or most complete study was used for the primary analysis. Sensitivity analysis was performed by vaccine type and by outcome measurement to assess the robustness of the results of primary meta-analyses. 


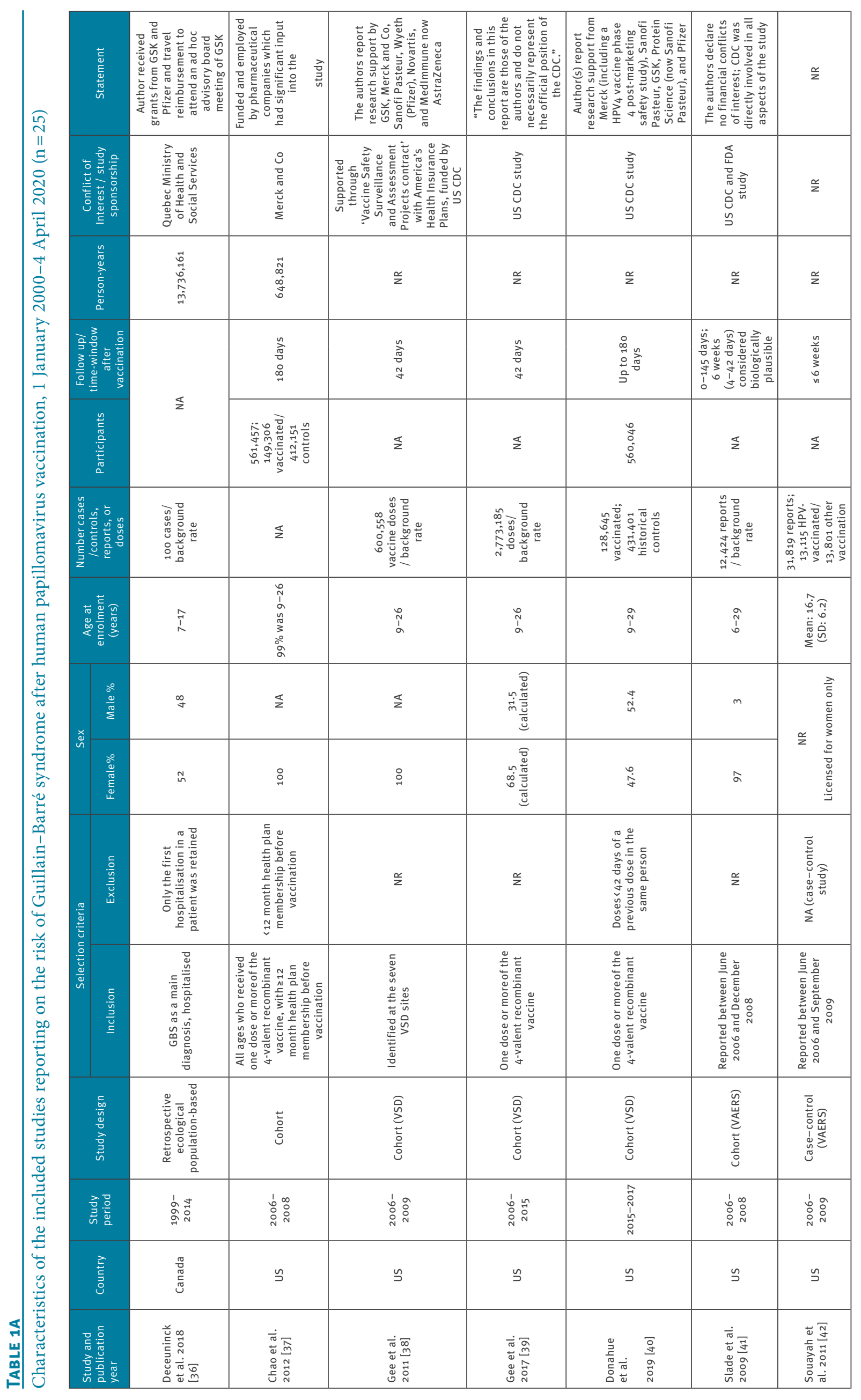




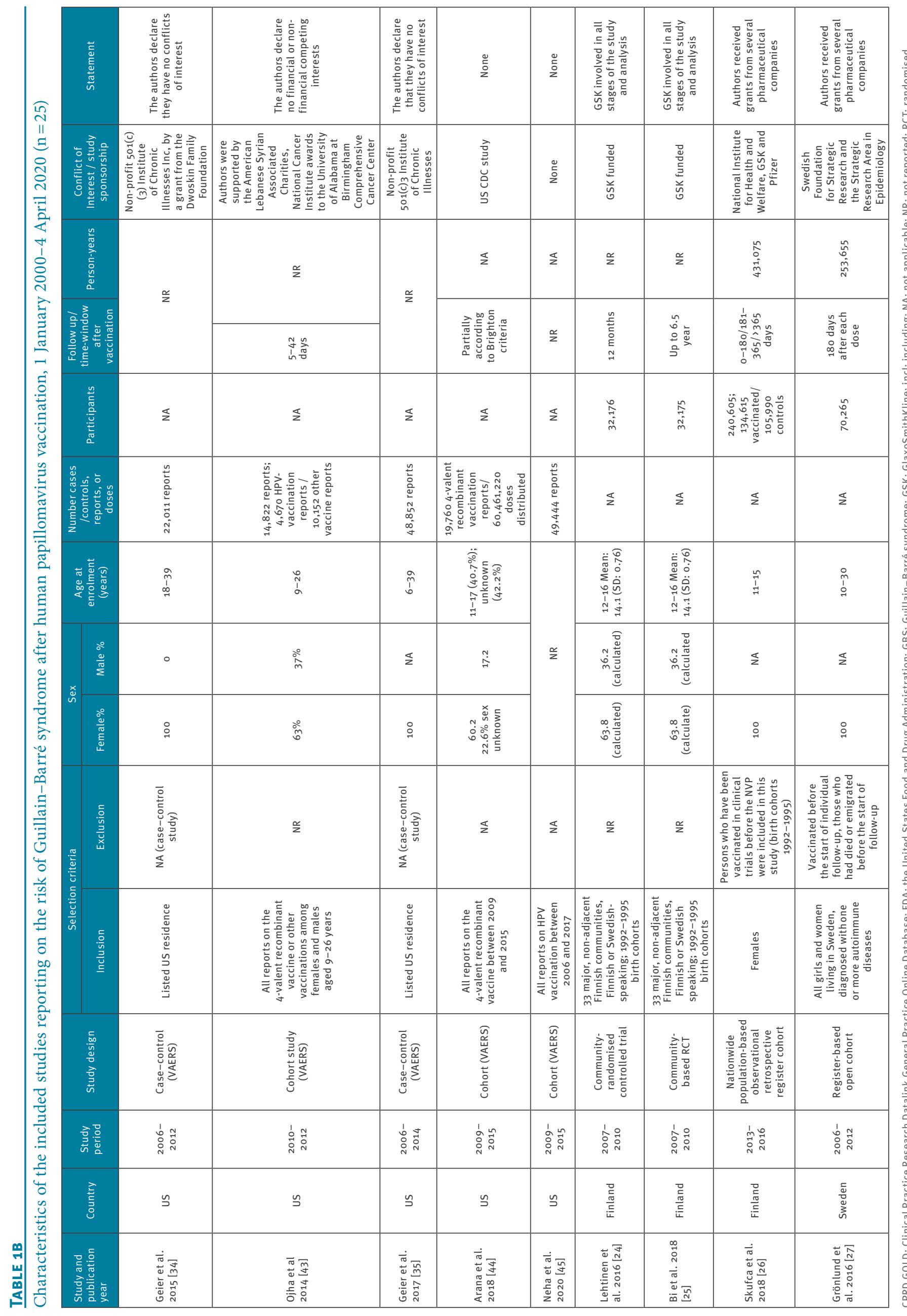




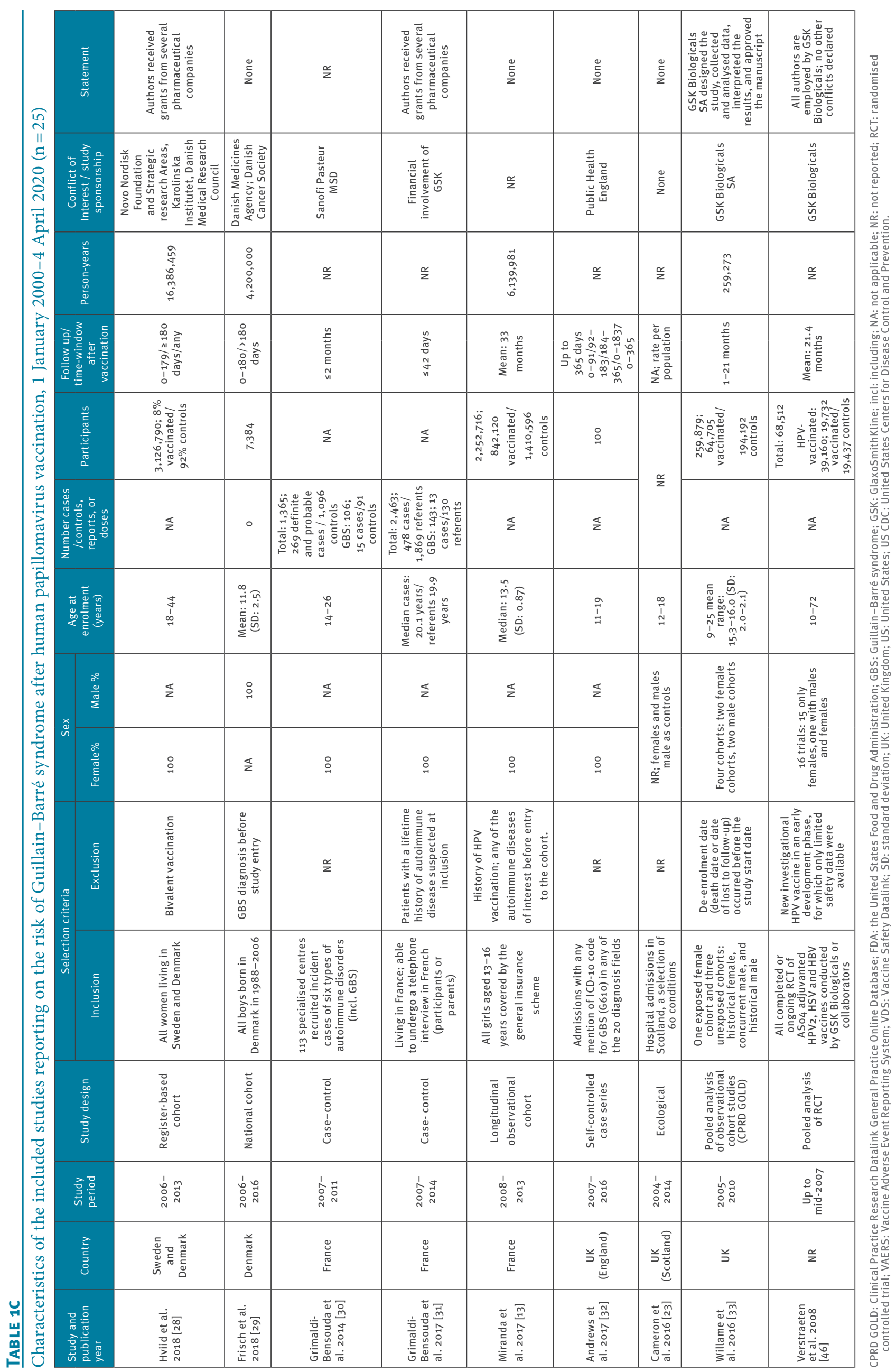


Public health perspective

To assess the public health implications of our findings, we calculated the number needed to harm $(\mathrm{NNH})$ to generate one additional case of GBS using GRADEprofiler version 3.6 (Informer Technologies, Los Angeles, United States (US)), based on the pooled findings of this study and the baseline risk for the age group of 10-19-year-olds (males: 0.97/100,000; females: 0.55/100,000; overall 0.75/100,000) [21]. For comparison, the number needed to vaccinate (NNV) was calculated in respect to the prevention of one case of cervical cancer [22].

\section{Results}

In total, we identified and screened 602 citations and included 25 studies (Figure 1).

\section{Study characteristics}

\section{Population}

The 25 included studies (Table 1) were conducted between 1999 and 2017. Twelve studies were conducted in Europe [13,23-33] and 12 studies were conducted in North America [34-45]. One study reported pooled RCT outcomes [46] without reporting the study location(s).

While most study populations comprised of adolescents, older and younger participants were also included. Age ranged from 6-72 years. We planned for inclusion of people aged 9 years and older [14] because the HPV vaccines are approved for people aged 9 years and older. However, for completeness, we decided not to exclude studies reporting on a broader age group. The majority of studies reported exclusively on the vaccination of girls and women. Twelve studies reported exclusively on females (100\% females in 11 studies and $97 \%$ females in one study), nine studies reported on both sexes (some of which had males only as comparator), one study reported exclusively on males and three studies did not report the sex of the participants (Table 1).

The included studies comprised data of more than 10 million reports in total. Of 25 studies, 14 reported the number of cases/controls, reports or vaccine doses (range: 4,133,370-4,415,894), 10 studies reported the number of participants (range: 6,622,607-6,843,326) and one study [23] did not report any number of participants, reports or case/control numbers.

Three studies had a randomised design: two studies reported on the same community-based randomised controlled trial $[24,25]$ and one was a pooled analysis of RCT [46]. The remaining 22 studies had a non-randomised design $[13,23,26-45]$ : 14 cohort studies, five case-control studies, two ecological studies and one self-controlled case series. The cohort studies were based on either registry data, adverse event notification data and/or clinical or hospital databases.

\section{Intervention}

Fourteen of 25 studies reported exclusively on vaccination with the 4-valent recombinant vaccine [27-30,3439,41-44] and five reported exclusively on the bivalent vaccine $[24-26,33,46]$ (Table 2 ). Three studies reported on both the 4 -valent recombinant vaccine and the bivalent vaccine $[13,31,32]$, while one reported only on the 9 -valent vaccine [40]. Two studies did not specify the type of HPV vaccine used $[23,45]$.

\section{Comparator}

Studies compared the risk of occurrence of GBS after HPV vaccination to either the risk of GBS after no vaccine (e.g. non-targeted populations such as boys), to another vaccine e.g. hepatitis B (HBV vaccine), meningococcus or influenza vaccine), or against historical background rates (Table 2). Case-control studies compared frequency of HPV vaccination in GBS cases to the frequency of HPV vaccination in controls; the controls being the general population or other adverse events reported to the vaccine safety registry.

\section{Outcome}

The duration of follow-up time varied, ranging from 42 to 180 days post-vaccination to the total accumulated number of person-years available in the registry or medical records. Eight studies reported the total follow-up time $[13,26-29,33,36,37]$, which adds up to $42,055,425$ reported person-years in total.

While five studies referred to the Brighton criteria for GBS case definitions $[30,38,39,41,44]$, in the majority of studies GBS diagnosis was based on original and expanded International Classification of Diseases codes (ICD-9 and ICD-10) as well as other coding systems such as Medcode, MedDRA and VAERS and freetext notes in medical files (Table 2 ).

\section{Risk of bias}

We summarised the findings of our risk of bias assessment in Figure 2 and Supplementary Table S3. The risk of bias in the community-based RCT by Lehtinen et al. and $\mathrm{Bi}$ et al. $[24,25]$ was considered to be low for most indicators, but high regarding the selection of the reported results, which was limited for GBS. We were not able to assess the risk of bias in the pooled analysis of 42 studies by Verstraeten et al. [46], of which 16 reported HPV vaccination, because of the complexity of the pooled design and lack of reporting of the key indicators for the risk of bias assessment. The risk of bias in 14 of 22 non-randomised studies was assessed as being critical and eight studies were assessed as being at serious risk of bias. The risk of bias was mostly introduced by the critical risk of confounding (i.e. lack of confounding correction), or because of the outcome measurement i.e. GBS diagnosis not based on Brighton criteria [15]. Risk of bias because of the classification of the intervention (vaccination status) was moderate when based on a registry and critical when self-reported. Less than 10 studies per outcome and per study design were available for pooling, which 


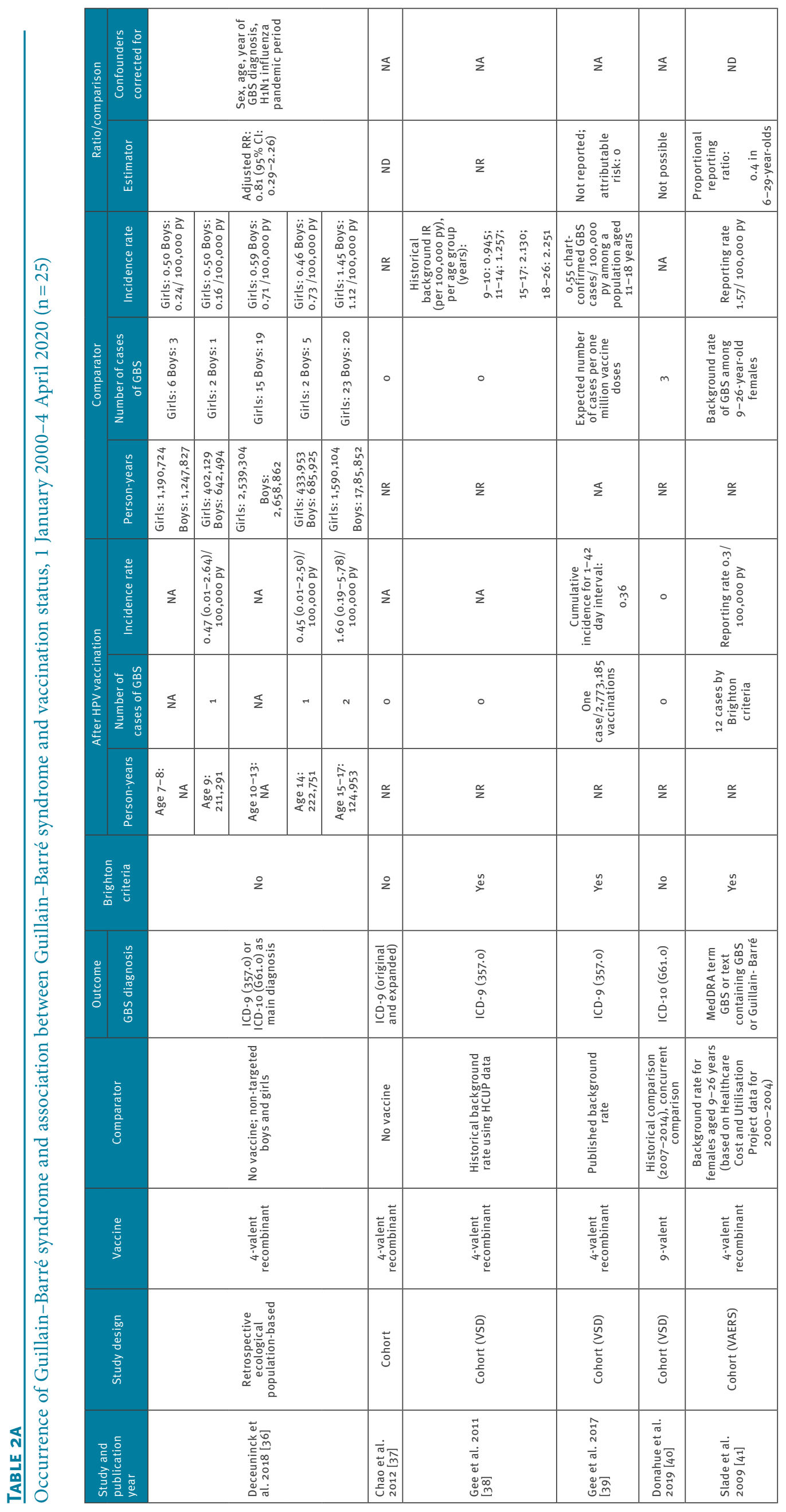




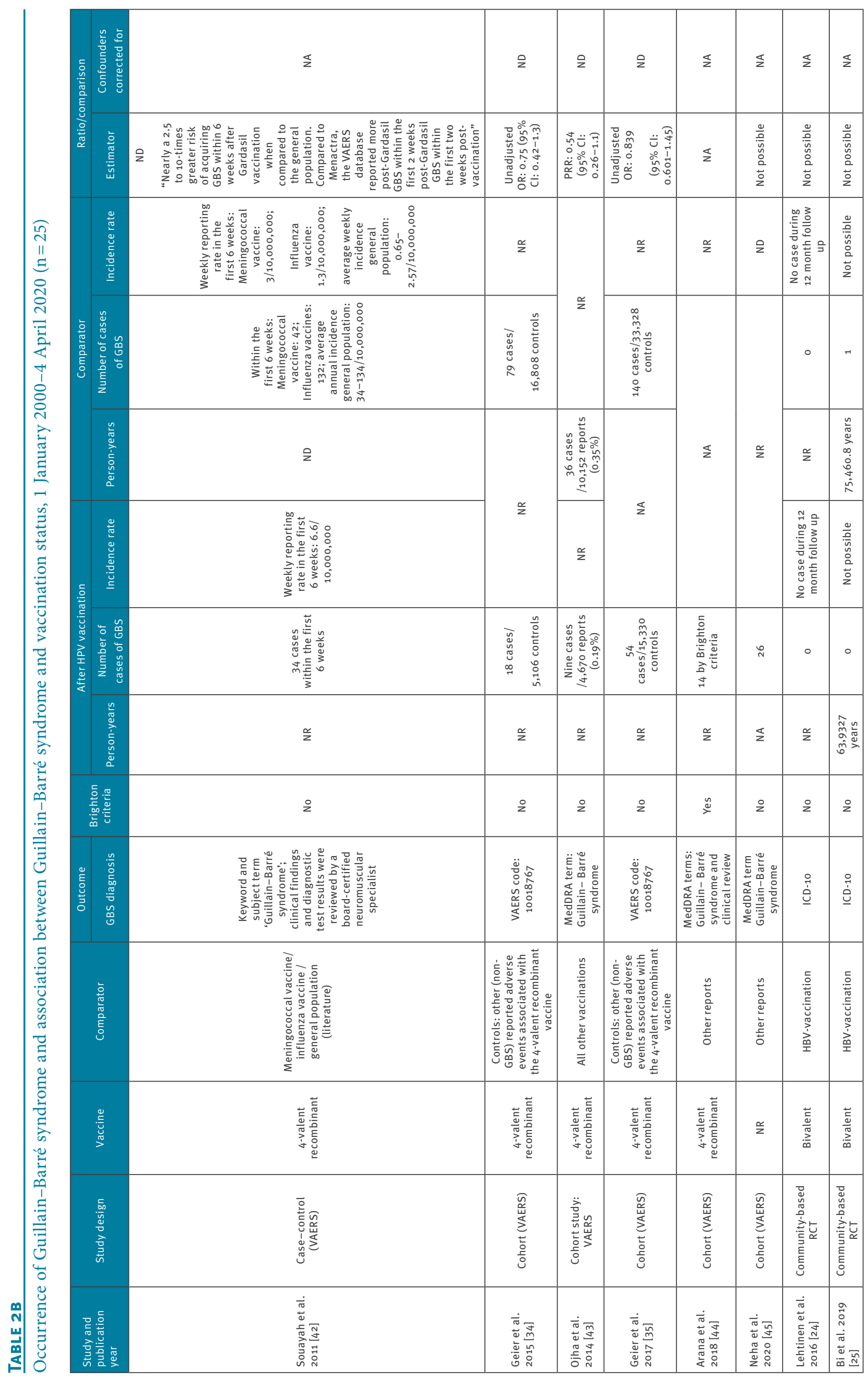




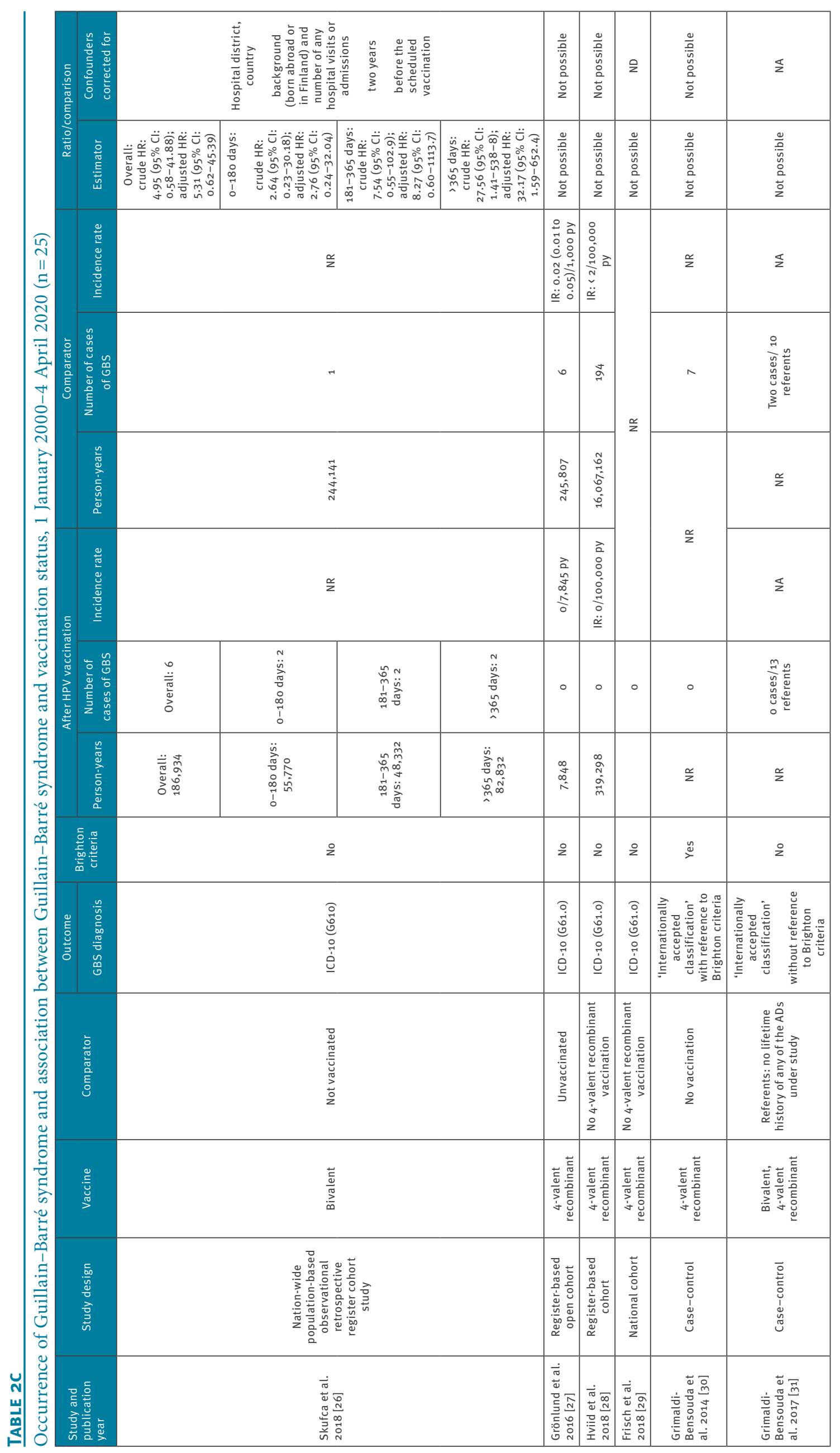

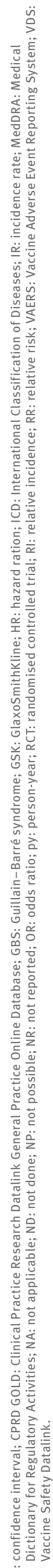




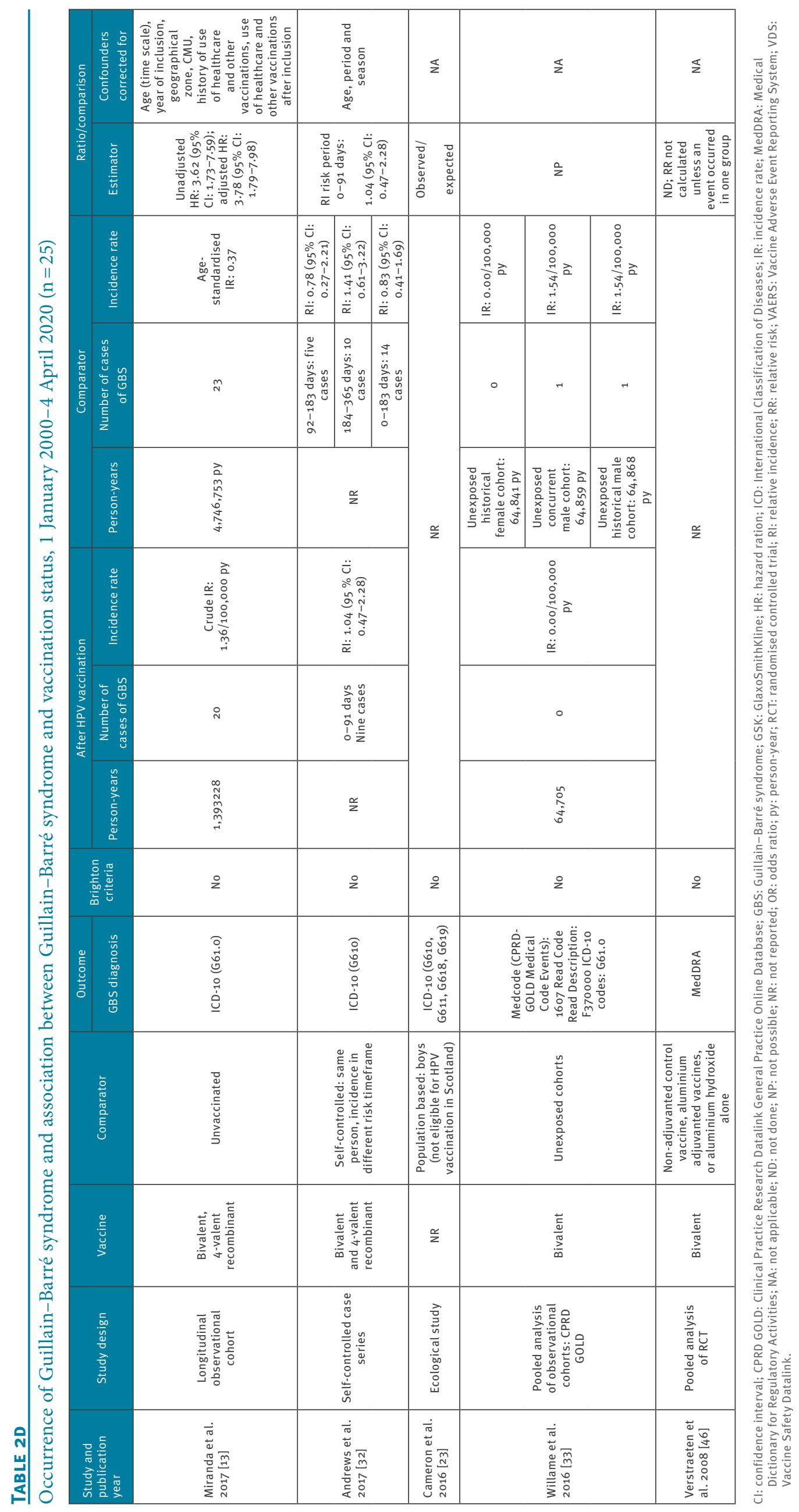


prevented us from systematically assessing publication bias by means of a funnel plot.

\section{Results of individual studies}

The reported occurrence of GBS following HPV vaccination is summarised in Table 2 and described by study design and by geographic region.

\section{Randomised studies}

Two randomised studies did not observe a single GBS case among people who received the HPV vaccine and found no increased risk of GBS after HPV vaccination. Lehtinen et al. [24] and $\mathrm{Bi}$ et al. [25] reported on a large community-based RCT in Finland. Among 32,176 adolescents, no GBS cases were diagnosed after the bivalent vaccine (or HBV vaccination). Verstraeten et al. [46] described the findings of a pooled analysis of all RCT of ASo4-adjuvanted bivalent vaccines, HSV and HBV vaccines. One GBS case was observed among 68,512 participants, in the control group.

\section{Non-randomised studies}

One cohort study [13] and two case-control studies $[30,31]$ investigated the potential association between the HPV vaccine and autoimmune disease in France. In the cohort study of more than two million girls by Miranda et al. [13], an increased risk of GBS was observed among vaccinated girls. There was an IR of 1.36 cases per 100,000 person-years among vaccinated individuals (20 cases), compared with 0.37 cases per 100,000 person-years among unvaccinated individuals (23 cases), with an adjusted hazard ratio (aHR) of 3.78 (95\% Cl: 1.79-7.98). The association was particularly marked in the first 2 months after vaccination and decreased over time, and did not differ with the type of HPV vaccine or whether or not GBS was preceded by a recent history of gastrointestinal or respiratory tract infection. Seasonality and calendar year did not affect the findings. In the two included case-control studies, no exposure to HPV vaccine was observed in cases with GBS $[30,31]$.

A cohort study with $3,126,790$ Swedish and Danish women [28] did not observe a single case of GBS among those who received the 4 -valent recombinant vaccine $(319,298$ person-years); 194 cases were observed among the unvaccinated $(16,067,162$ personyears). Grönlund et al. [27] studied a cohort of 70,265 girls and women with pre-existing autoimmune disease in Sweden. None of those who received the 4 -valent recombinant vaccine developed new-onset GBS $(7,845$ person-years); six cases of GBS were observed among the unvaccinated $(245,807$ person-years); the IRR could not be calculated. Frisch et al. [29] studied 7,384 Danish boys born in 1988-2006. No case of GBS was observed after the 4-valent recombinant vaccine during the four million person-years of follow up in 2006-2016.

In Finland, Skufca et al. [26] investigated baseline annual, pre-vaccination, and post-vaccination period incidences of GBS, followed by a nationwide population-based observational cohort study among 240,605 women that compared the risk of GBS between those exposed and not exposed to the bivalent vaccine. There was no increase in GBS incidence in the post-vaccination period in neither men nor women. Cox regression showed a statistically non-significant trend towards increased risk of GBS after HPV vaccination among women, with an aHR of 5.31 (95\% confidence interval (Cl): $0.62-45.39)$. A year after vaccination, the aHR was substantially increased at 32.17 with a wide $\mathrm{Cl}$ (95\% Cl: 1.59-652.4).

A self-controlled case series from England [32] compared GBS incidence following vaccination with the bivalent and 4-valent recombinant vaccines in different risk timeframes. The relative incidence was 1.04 (95\% Cl: $0.47-2.28$ ) for the 3-month risk period and 0.83 (95\% Cl: $0.41-1.69)$ and 1.10 (95\% Cl: $0.57-2.14$ ) for the 6 - and 12-month period, respectively. Based on this finding the authors excluded a risk in the order of one GBS case per million HPV doses.

Both ecological studies, in Scotland [23] (trend analysis, no data extraction possible) and in Canada [36] (aRR: 0.81; 95\% Cl: 0.29-2.26), observed no increased risk of GBS following HPV vaccination.

Eleven studies reported data from the US: seven studies based on the Vaccine Adverse Event Reporting (VAERS) [47] registry, three based on the Vaccine Safety Datalink (VSD) safety monitoring data [48] and one cohort study. Seven studies reported 2006-2017 data on HPV vaccination from the VAERS registry.

A descriptive summary of 12,424 VAERS reports between 2006 and 2008 by Slade et al. [41] reported 0.3 confirmed GBS cases per 100,000 person-years following the 4 -valent recombinant vaccine, compared with 1.57 cases per 100,000 person-years following all other vaccinations in the same age group. The proportional reporting ratio for GBS after the 4 -valent recombinant vaccine was 0.4 and did not meet the screening criteria for signal detection. Arana et al. [44] provided an update of the analysis, and summarised 19,760 VAERS reports from 2009 to 2015 . In total, 59 reports of GBS have been identified, of which 14 (24\%) met the Brighton Collaboration criteria at Level $1(n=5)$ which is the highest level of diagnostic certainty, or Level 2 $(n=9)$. The 4 -valent recombinant vaccine was given alone in six reports. The crude reporting rate of GBS was 0.98 per one million 4 -valent recombinant vaccine doses distributed, based on an estimated 60,461,220 doses distributed in the US in that time period (20092015). Additionally, Neha et al. [45] reviewed all clinically relevant vaccine event combinations following HPV vaccination as reported to VAERS between 2006 and 2017; no safety concern was identified. Souayah et al. [42] compared the weekly reporting rates of GBS, in the 6 weeks after vaccination against HPV genotype 4 (6.6 cases per week/10,000,000 people), meningococcal vaccine (3 cases per week/10,000,000 population), 
Summary of risk of bias assessment, 1 January 2000-4 April $2020(\mathrm{n}=25)^{\mathrm{a}}$
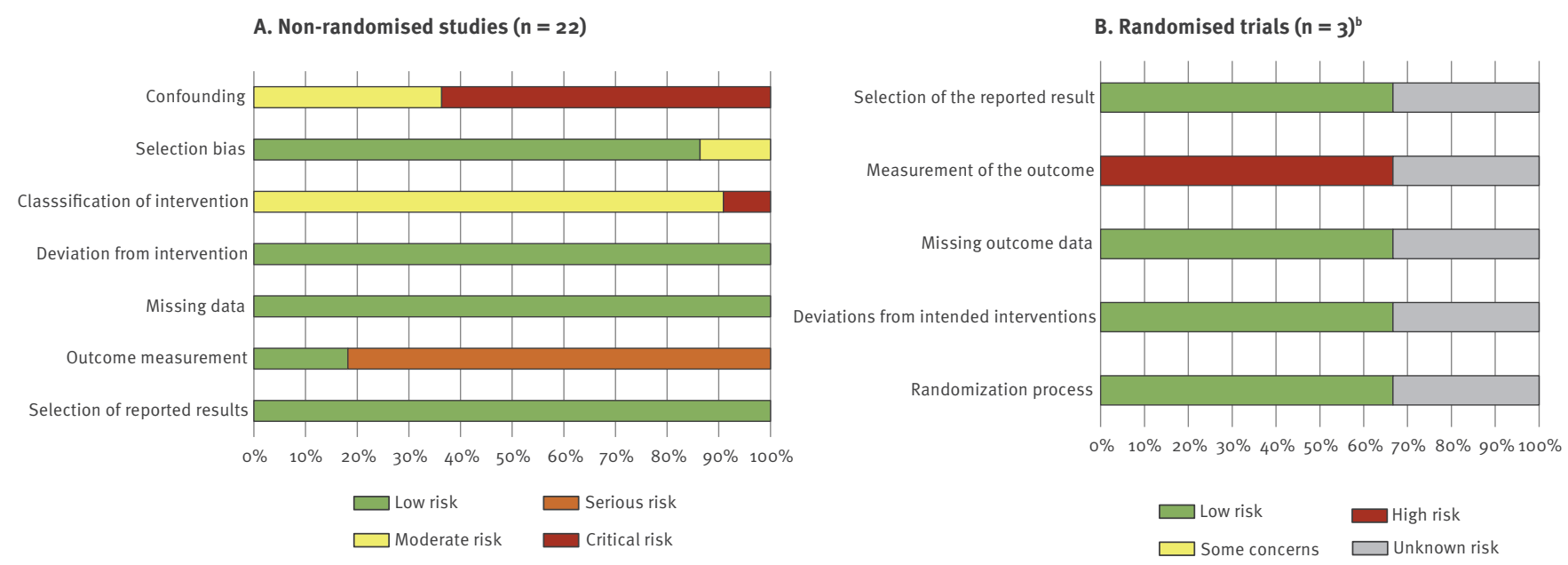

a Full results are provided in Supplementary Table S4.

b Two of three publications are based on the same community-randomised controlled trial (interim and end-of-study results) [24,25].

and influenza vaccine (1.3 cases per week/10,000,000), based on VAERS reports between 2006 and 2009. Furthermore, these rates were compared with the expected weekly incidence in the general population $(0.65-2.57$ cases per week/10,000,000) based on a literature review. The authors summarise these findings as "There was nearly a 2.5-to 10-times greater risk of acquiring GBS within 6 weeks after Gardasil vaccination when compared with the general population." [42]. For the period of 2010-2012, Ojha et al. [43] compared the reporting of GBS cases to VAERS following vaccination with the 4 -valent recombinant vaccine (nine cases $/ 4,670$ reports; $0.19 \%)$ to those of other vaccines (36 cases/10,152 reports; $0.35 \%$ ) with a proportional reporting ratio of 0.54 ( $95 \% \mathrm{Cl}: 0.26-1.1)$.

Two case-control studies were based on data from 22,011 VAERS reports in the period of 2006-2012 targeting 18-39-year-old women [34] and on 48,852 reports in 2006-2014 targeting 6-39-year-old girls and women [35]. Both studies found no association between GBS and the 4-valent recombinant vaccine, with an unadjusted OR of 0.75 (95\% Cl: 0.42-1.3) and 0.84 (95\% Cl: 0.60-1.15), respectively.

Three studies reported on 2006-2017 VSD safety monitoring data of the bivalent vaccine and the 4-valent recombinant vaccine [38-40]. Two studies on the 4-valent recombinant vaccine based on the 2006-2015 VSD safety monitoring data found lower GBS incidences following vaccination, compared with the background rates. Gee 2011 et al. [38] observed one case of GBS among the 600,558 4-valent recombinant vaccine doses administered between 2006 and 2009, of which medical record review revealed that this was not an incident case. Gee 2017 et al. [39] observed one case of GBS among 2,773,185 4-valent recombinant vaccine doses administered between 2006 and 2015 (IR: 0.36/1,000,000 doses; one-sided $95 \% \mathrm{Cl}: 1.71$ ). Donahue et al. [40] reported on safety data of the 9-valent vaccine based on 128,645 doses given between 2015 and 2017, and did not observe GBS among the vaccinated; three cases of GBS were reported in the historical comparison group.

Additionally, Chao et al. [37] conducted a cohort study in California among 189,629 women who received one dose or more of the 4 -valent recombinant vaccine in the period of 2006-2008 and did not observe a single GBS case among both vaccinated and unvaccinated women.

\section{Meta-analysis}

Seven studies reported an effect-estimate suitable for meta-analysis $[13,26,32,34-36,43]$. The remaining 18 studies were not suitable because only descriptive outcomes were available, or because one or both groups did not observe a single case. Two studies by Geier et al. published findings with overlap in data based on the VAERS dataset $[34,35]$, with similar findings. The effect estimate by Geier et al. 2017 [35] was used in the primary analyses and the Geier et al. 2015 [34] estimate in the sensitivity analysis. Therefore, the results of the meta-analysis show findings of six studies.

Meta-analysis yielded a pooled random-effects model ratio of HPV vaccination on GBS of 1.21 (95\% Cl: $0.60-$ $2.43) ; I^{2}=72 \%(95 \% \mathrm{Cl}: 36-88)$ (Figure 3 ). Sensitivity analysis including Geier et al. 2015 [34] instead of Geier et al. 2017 [35], yielded similar results: 1.19 (95\% $\mathrm{Cl}: 0.58-2.43) ; \mathrm{I}^{2}=73 \%(95 \% \mathrm{Cl}: 37-88)$. The pooled estimate was 0.88 ( $95 \% \mathrm{Cl}: 0.60-1.31)$ for self-/casecontrolled studies and 1.49 (95\% Cl: $0.50-4.38)$ for 
Meta-analysis of studies reporting an effect estimate of the risk of Guillain-Barré syndrome after HPV vaccination, by study design, 1 January 2000-4 April $2020(\mathrm{n}=7)^{\mathrm{a}, \mathrm{b}}$

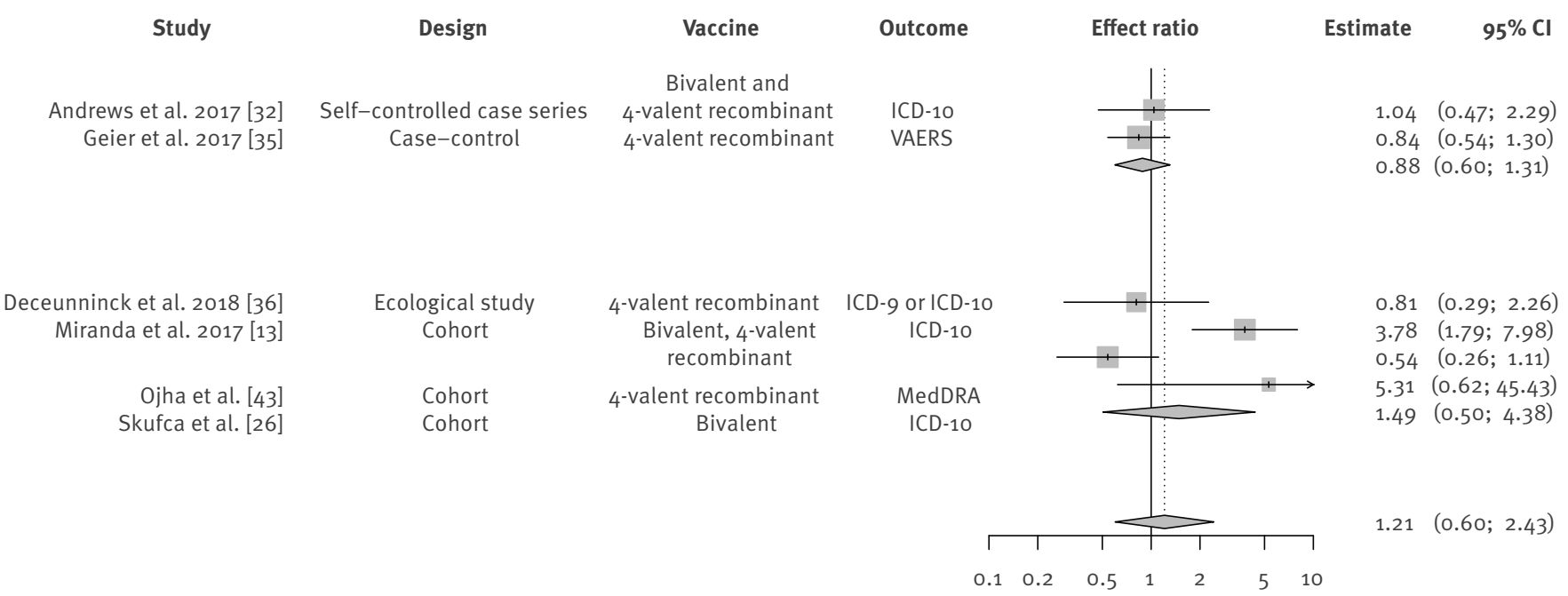

$\mathrm{CI}$ : confidence interval; ICD: International Statistical Classification of Diseases and Related Health Problems (International Classification of Diseases); VAERS: vaccine adverse event reporting system.

${ }^{a}$ Meta-analysis yielded a pooled random-effects model ratio of HPV vaccination on GBS of 1.21 (95\% Cl: $\left.0.60-2.43\right) ; \mathrm{I} 2=72 \%(95 \% \mathrm{Cl}: 36-88)$.

b Two studies published findings with a large overlap in data based on the VAERS dataset [34,35] with similar findings. The effect estimate by Geier et al. 2017 [35] was used in the primary analyses and Geier et al. 2015 [34] estimate in the sensitivity analysis. Therefore, the results of the meta-analysis show findings of six studies. When substituting the effect estimate of Geier et al. 2017 for Geier et al. 2015 (OR: 0.75 ; $95 \% \mathrm{Cl}: 0.42-1.3)$, the pooled estimate for case-control studies is 1.19 (95\% Cl: $0.58-2.43), \mathrm{I} 2=72 \%(95 \% \mathrm{Cl}: 37-88)$.

All effect (adjusted) effect estimates (odds ratios, hazard ratios, relative risks, proportional reporting ratio, relative incidence, incidence rate ratio) are combined in one overall ratio.

cohort studies. Findings of the subgroup analysis by vaccine type (bivalent vaccine, 4-valent recombinant vaccine or both) and outcome measure are provided in the Supplement.

Additional subgroup analysis by Brighton vs nonBrighton GBS case definition was not possible because all seven studies used non-Brighton criteria. The included studies were heterogeneous in terms of study design, analysis and reporting, which was also reflected in the high $\mathrm{I}^{2}$, which indicates the percentage of variability in the effect sizes which is not caused by sampling error.

\section{Quality of the body of evidence}

According to the GRADE approach, the quality of the body of evidence is very low. We had to downgrade the quality of evidence three times: (i) for risk of bias (residual confounding at least); (ii) for imprecision (wide $95 \% \mathrm{Cl}$ around the pooled estimate including substantial benefit as well as substantial harm) and; (iii) heterogeneity (inconsistency; $\left.\right|^{2}=72 \%$ ).

\section{Number needed to harm and number needed to vaccinate}

Translating the pooled random-effect ratio of 1.21 (95\% $\mathrm{Cl}: 0.60-2.43)$ to the number needed to harm (NNH), we estimated that one million people need to take the $\mathrm{HPV}$ vaccine to generate one case of GBS ( $95 \% \mathrm{Cl}:-3$ to 8 cases). In contrast, 324 (80\% credibility interval: 195-757) people need to be vaccinated to prevent one cases of cervical cancer [48].

\section{Discussion}

The results of our systematic review and meta-analysis indicate that absolute risk of GBS after HPV vaccination is low. Reported historical background rates of GBS incidence were between 0.55 and 2.25 cases per 100,000 person-years [38,39]. A slightly increased RR of GBS after HPV vaccination is low, far away from statistical significance based on findings from our metaanalysis. From a public health point of view, up to one million people would need to be vaccinated to generate one additional case of GBS, while the NNV to prevent one case of cervical cancer is ca 300.

We performed a comprehensive and systematic search on this topic that includes all licenced HPV vaccines. It was specifically targeted at investigating the association with GBS, in the context of other reviews that focussed on the potential association between HPV vaccination and autoimmune and/or neurological diseases [49-51]. 
The quality of our findings depended on the quality of the studies, which were largely registry studies and based on non-Brighton GBS outcomes. There was risk of bias because of large heterogeneity in the design and reporting of the studies, as well as the control groups. Confounding was the biggest limiting factor of the quality of the evidence, because many studies were not designed to correct for confounding and cohorts were highly confounded. Often, the control group was not matched based on sex or age group. Outcome ascertainment was challenging, given the heterogeneity of case definitions for GBS; only one of five studies used the Brighton criteria.

The follow-up period for the detection of GBS varied between studies and many of the cohorts or registrybased studies were partially underpowered by design because of the rarity of GBS. In the three studies that signalled increased risk of GBS after HPV vaccination, conflicting temporal trends were reported. In the study by Miranda et al. [13] the association between vaccination and GBS was particularly marked in the first 2 months after vaccination and decreased over time, while Skufca et al. [26] reported a substantial increase in the association (with very wide $\mathrm{Cl}$ ). Souayah et al. [29] also noted increased reporting of GBS during the first 6 weeks after vaccination, although interpreting this trend was challenging in this VAERS reporting study since all five other studies reporting VAERS data found no association between HPV vaccination and GBS. Interpretation of these results in terms of causality should be made with caution.

In future studies, consensus on the case definition for GBS and the risk timeframe is needed to generate uniform and comparable findings. Studies in settings with gender-neutral vaccination policies are required to further assess the risk of GBS after HPV vaccination among boys and men. Furthermore, studies should be expanded to geographical areas outside of western Europe and North America, where HPV vaccination is being implemented on large scale. To generate the highest quality of evidence on this topic, we recommend further research with a self-controlled case series design using Brighton-outcomes. The self-controlled case series design has been proved most suitable for rare events and limits confounding to time-dependent confounding [21], as also used to assess the risk of intussusception after rotavirus vaccination [52].

This study aims to provide up to date vaccination safety information for healthcare providers and policymakers as well as the general public [53]. Transparent communication of potential safety issues is essential to build trust and strengthen confidence in HPV vaccination. Concern about vaccine safety is one of the key determinants of vaccine hesitancy and poses a threat to public health. Healthcare providers play an important role in communicating information on HPV safety [54]. The low potential risk of GBS after HPV vaccination should have minimal impact on the risk consideration for HPV vaccination programmes, reassure vaccine confidence and ultimately increase vaccination rates.

\section{Conflict of interest}

TSB is a fellow of the Centre for Disease Prevention and Control (ECDC) Fellowship Programme, supported financially by ECDC. The views and opinions expressed herein do not state or reflect those of ECDC. ECDC is not responsible for the data, information collation and analysis and cannot be held liable for conclusions or opinions drawn.

\section{Authors' contributions}

TSB conducted the database searches, screened and assessed studies as primary reviewer, extracted the data, conducted the meta-analysis and wrote the first version of the manuscript. TH conceived the study, screened and assessed studies as second reviewer and held general oversight of the conducted work. TSB, TH, BB, LC and OW contributed to the interpretation of the data, provided important intellectual content, revised and approved to the manuscript.

\section{References}

1. Harder T, Wichmann O, Klug SJ, van der Sande MAB, WiesePosselt M. Efficacy, effectiveness and safety of vaccination against human papillomavirus in males: a systematic review. BMC Med. 2018;16(1):110. https://doi.org/10.1186/s12916-0181098-3 PMID: 30016957

2. Schiller JT, Castellsagué X, Garland SM. A review of clinical trials of human papillomavirus prophylactic vaccines. Vaccine. 2012;30(Suppl 5):F123-38. https://doi.org/10.1016/j. vaccine.2012.04.108 PMID: 23199956

3. Drolet M, Bénard É, Pérez N, Brisson M, Ali H, Boily M-C et al. Population-level impact and herd effects following the introduction of human papillomavirus vaccination programmes: updated systematic review and meta-analysis. Lancet. 2019;394(10197):497-509. https://doi.org/10.1016/ S0140-6736(19)30298-3 PMID: 31255301

4. Sha BE. Adult immunization update. JAMA. 2019;322(11):1096 7. https://doi.org/10.1001/jama.2019.12739 PMID: 31424523

5. Palmer T, Wallace L, Pollock KG, Cuschieri K, Robertson C, Kavanagh $\mathrm{K}$, et al. Prevalence of cervical disease at age 20 after immunisation with bivalent HPV vaccine at age 12-13 in Scotland: retrospective population study. BMJ. 2019;365:l1161. https://doi.org/10.1136/bmj.l1161 PMID: 30944092

6. Patel EU, Grabowski MK, Eisenberg AL, Packman ZR, Gravitt $P E$, Tobian AAR. Increases in Human Papillomavirus vaccination among adolescent and young adult males in the United States, 2011-2016. J Infect Dis. 2018;218(1):109-13. https://doi. org/10.1093/infdis/jiy165 PMID: 29584878

7. Bruni L, Diaz M, Barrionuevo-Rosas L, Herrero R, Bray F, Bosch FX, et al. Global estimates of human papillomavirus vaccination coverage by region and income level: a pooled analysis. Lancet Glob Health. 2016;4(7):e453-63. https://doi. org/10.1016/S2214-109X(16)30099-7 PMID: 27340003

8. DeStefano F, Bodenstab HM, Offit PA. Principal controversies in vaccine safety in the United States. Clin Infect Dis. 2019;69(4):726-31. https://doi.org/10.1093/cid/ciz135 PMID: 30753348

9. Jiang HY, Shi YD, Zhang X, Pan LY, Xie YR, Jiang CM, et al. Human papillomavirus vaccination and the risk of autoimmune disorders: A systematic review and meta-analysis. Vaccine. 2019;37(23):3031-9. https://doi.org/10.1016/j. vaccine.2019.04.049 PMID: 31036452

10. McGrogan A, Madle GC, Seaman HE, de Vries CS. The epidemiology of Guillain-Barré syndrome worldwide. A systematic literature review. Neuroepidemiology. 2009;32(2):150-63. https://doi.org/10.1159/000184748 PMID: 19088488

11. Sejvar JJ, Baughman AL, Wise M, Morgan OW. Population incidence of Guillain-Barré syndrome: a systematic review and meta-analysis. Neuroepidemiology. 2011;36(2):123-33. https:// doi.org/10.1159/000324710 PMID: 21422765

12. Haber P, Sejvar J, Mikaeloff Y, DeStefano F. Vaccines and Guillain-Barré syndrome. Drug Saf. 2009;32(4):309-23. 
https://doi.org/10.2165/00002018-200932040-00005 PMID: 19388722

13. Miranda S, Chaignot C, Collin C, Dray-Spira R, Weill A, Zureik $M$. Human papillomavirus vaccination and risk of autoimmune diseases: A large cohort study of over 2 million young girls in France. Vaccine. 2017;35(36):4761-8. https://doi.org/10.1016/j. vaccine.2017.06.030 PMID: 28750853

14. Boender TS, Harder T. Risk of Guillain-Barré Syndrome (GBS) after vaccination against human papillomavirus (HPV). PROSPERO No. \#CRD42019123533. 2019. Available from: https://www.crd.york.ac.uk/prospero/display_record. php?ID=CRD42019123533

15. Liberati A, Altman DG, Tetzlaff J, Mulrow C, Gøtzsche PC, Ioannidis JP, et al. The PRISMA statement for reporting systematic reviews and meta-analyses of studies that evaluate health care interventions: explanation and elaboration. PLoS Med. 2009;6(7):e1000100. https://doi.org/10.1371/journal. pmed.1000100 PMID: 19621070

16. Sejvar J,, Kohl KS, Gidudu J, Amato A, Bakshi N, Baxter R, et al. Guillain-Barré syndrome and Fisher syndrome: case definitions and guidelines for collection, analysis, and presentation of immunization safety data. Vaccine. 2011;29(3):599612. https://doi.org/10.1016/j.vaccine.2010.06.003 PMID: 20600491

17. Sterne JAC, Savović J, Page MJ, Elbers RG, Blencowe NS, Boutron I, et al. RoB 2: a revised tool for assessing risk of bias in randomised trials. BMJ. 2019;366:14898. https://doi. org/10.1136/bmj.l4898 PMID: 31462531

18. Sterne JA, Hernán MA, Reeves BC, Savović J, Berkman ND, Viswanathan $M$, et al. ROBINS-I: a tool for assessing risk of bias in non-randomised studies of interventions. BMJ. 2016;355:i4919. https://doi.org/10.1136/bmj.i4919 PMID: 27733354

19. Guyatt G, Oxman AD, Akl EA, Kunz R, Vist G, Brozek J, et al. GRADE guidelines: 1 . Introduction-GRADE evidence profiles and summary of findings tables. J Clin Epidemiol. 2011;64(4):38394. https://doi.org/10.1016/j.jclinepi.2010.04.026 PMID: 21195583

20. Schünemann HJ, Cuello C, Akl EA, Mustafa RA, Meerpohl JJ, Thayer K, et al. GRADE guidelines: 18. How ROBINS-I and other tools to assess risk of bias in nonrandomized studies should be used to rate the certainty of a body of evidence. Clin Epidemiol. 2019;111:105-14. https://doi.org/10.1016/j. jclinepi.2018.01.012 PMID: 29432858

21. Farrington CP. Control without separate controls: evaluation of vaccine safety using case-only methods. Vaccine. 2004;22(1516):2064-70. https://doi.org/10.1016/j.vaccine.2004.01.017 PMID: 15121324

22. Brisson M, Van de Velde N, De Wals P, Boily M-C. Estimating the number needed to vaccinate to prevent diseases and death related to human papillomavirus infection. CMAJ. 2007;177(5):464-8. https://doi.org/10.1503/cmaj.061709 PMID: 17709404

23. Cameron RL, Ahmed S, Pollock KGJ. Adverse event monitoring of the human papillomavirus vaccines in Scotland. Intern Med J. 2016;46(4):452-7. https://doi.org/10.1111/imj.13005 PMID: 26765074

24. Lehtinen M, Eriksson T, Apter D, Hokkanen M, Natunen K, Paavonen J, et al. Safety of the human papillomavirus (HPV)16/18 ASo4-adjuvanted vaccine in adolescents aged 12-15 years: Interim analysis of a large community-randomized controlled trial. Hum Vaccin Immunother. 2016;12(12):317785. https://doi.org/10.1080/21645515.2016.1183847 PMID: 27841725

25. Bi D, Apter D, Eriksson T, Hokkanen M, Zima J, Damaso S, et al. Safety of the ASo4-adjuvanted human papillomavirus (HPV)$16 / 18$ vaccine in adolescents aged $12-15$ years: end-of-study results from a community-randomized study up to 6.5 years. Hum Vaccin Immunother. 2020;16(6):1392-403. https://doi.org /10.1080/21645515.2019.1692557 PMID: 31829767

26. Skufca J, Ollgren J, Artama M, Ruokokoski E, Nohynek H, Palmu AA. The association of adverse events with bivalent human papilloma virus vaccination: A nationwide registerbased cohort study in Finland. Vaccine. 2018;36(39):5926-33. https://doi.org/10.1016/j.vaccine.2018.06.074 PMID: 30115524

27. Grönlund O, Herweijer E, Sundström K, Arnheim-Dahlström L. Incidence of new-onset autoimmune disease in girls and women with pre-existing autoimmune disease after quadrivalent human papillomavirus vaccination: a cohort study. J Intern Med. 2016;280(6):618-26. https://doi. org/10.1111/joim.12535 PMID: 27478093

28. Hviid A, Svanström H, Scheller NM, Grönlund O, Pasternak $B$, Arnheim-Dahlström L. Human papillomavirus vaccination of adult women and risk of autoimmune and neurological diseases. J Intern Med. 2018;283(2):154-65. https://doi. org/10.1111/joim.12694 PMID: 29044769
29. Frisch $M$, Besson $A$, Clemmensen $K K B$, Valentiner-Branth P, Mølbak K, Hviid A. Quadrivalent human papillomavirus vaccination in boys and risk of autoimmune diseases, neurological diseases and venous thromboembolism. Int J Epidemiol. 2018;47(2):634-41. https://doi.org/10.1093/ije/ dyx273 PMID: 29425361

30. Grimaldi-Bensouda L, Guillemot D, Godeau B, Bénichou J, Lebrun-Frenay C, Papeix C, et al. Autoimmune disorders and quadrivalent human papillomavirus vaccination of young female subjects. J Intern Med. 2014;275(4):398-408. https:// doi.org/10.1111/joim.12155 PMID: 24206418

31. Grimaldi-Bensouda L, Rossignol M, Koné-Paut I, Krivitzky A, Lebrun-Frenay C, Clet J, et al. Risk of autoimmune diseases and human papilloma virus (HPV) vaccines: Six years of casereferent surveillance. J Autoimmun. 2017;79:84-90. https:// doi.org/10.1016/j.jaut.2017.01.005 PMID: 28190705

32. Andrews N, Stowe J, Miller E. No increased risk of Guillain-Barré syndrome after human papilloma virus vaccine: A self-controlled case-series study in England. Vaccine. 2017;35(13):1729-32. https://doi.org/10.1016/j. vaccine.2017.01.076 PMID: 28245941

33. Willame C, Rosillon D, Zima J, Angelo MG, Stuurman AL, Vroling $\mathrm{H}$, et al. Risk of new onset autoimmune disease in 9- to 25-year-old women exposed to human papillomavirus-16/18 ASo4-adjuvanted vaccine in the United Kingdom. Hum Vaccin Immunother. 2016;12(11):2862-71. https://doi.org/10.1080/216 45515.2016.1199308 PMID: 27428517

34. Geier DA, Geier MR. A case-control study of quadrivalent human papillomavirus vaccine-associated autoimmune adverse events. Clin Rheumatol. 2015;34(7):1225-31. https://doi. org/10.1007/s10067-014-2846-1 PMID: 25535199

35. Geier DA, Geier MR. Quadrivalent human papillomavirus vaccine and autoimmune adverse events: a case-control assessment of the vaccine adverse event reporting system (VAERS) database. Immunol Res. 2017;65(1):46-54. https:// doi.org/10.1007/s12026-016-8815-9 PMID: 27406735

36. Deceuninck G, Sauvageau C, Gilca V, Boulianne N, De Serres $\mathrm{G}$. Absence of association between Guillain-Barré syndrome hospitalizations and HPV-vaccine. Expert Rev Vaccines. 2018;17(1):99-102. https://doi.org/10.1080/14760584.2018.13 88168 PMID: 28972438

37. Chao C, Klein NP, Velicer CM, Sy LS, Slezak JM, Takhar H, et al. Surveillance of autoimmune conditions following routine use of quadrivalent human papillomavirus vaccine. J Intern Med. 2012;271(2):193-203. https://doi.org/10.1111/j.13652796.2011.02467.x PMID: 21973261

38. Gee J, Naleway A, Shui I, Baggs J, Yin R, Li R, et al. Monitoring the safety of quadrivalent human papillomavirus vaccine: findings from the Vaccine Safety Datalink. Vaccine. 2011;29(46):8279-84. https://doi.org/10.1016/j. vaccine.2011.08.106 PMID: 21907257

39. Gee J, Sukumaran L, Weintraub E. Risk of GuillainBarré Syndrome following quadrivalent human papillomavirus vaccine in the Vaccine Safety Datalink. Vaccine. 2017;35(43):5756-8. https://doi.org/10.1016/j. vaccine.2017.09.009 PMID: 28935469

40. Donahue JG, Kieke BA, Lewis EM, Weintraub ES, Hanson $\mathrm{KE}, \mathrm{McCl}$ ure DL, et al. Near real-time surveillance to assess the safety of the 9-valent Human Papillomavirus Vaccine. Pediatrics. 2019;144(6):e20191808. https://doi.org/10.1542/ peds.2019-1808 PMID: 31740498

41. Slade BA, Leidel L, Vellozzi C, Woo EJ, Hua W, Sutherland A, et al. Postlicensure safety surveillance for quadrivalent human papillomavirus recombinant vaccine. JAMA. 2009;302(7):750-7. https://doi.org/10.1001/jama.2009.1201 PMID: 19690307

42. Souayah N, Michas-Martin PA, Nasar A, Krivitskaya N, Yacoub HA, Khan H, et al. Guillain-Barré syndrome after Gardasil vaccination: data from Vaccine Adverse Event Reporting System 2006-2009. Vaccine. 2011;29(5):886-9. https://doi. org/10.1016/j.vaccine.2010.09.020 PMID: 20869467

43. Ojha RP, Jackson BE, Tota JE, Offutt-Powell TN, Singh KP, Bae S. Guillain-Barre syndrome following quadrivalent human papillomavirus vaccination among vaccine-eligible individuals in the United States. Hum Vaccin Immunother. 2014;10(1):2327. https://doi.org/10.4161/hv.26292 PMID: 24013368

44. Arana JE, Harrington T, Cano M, Lewis P, Mba-Jonas A, Rongxia L, et al. Post-licensure safety monitoring of quadrivalent human papillomavirus vaccine in the Vaccine Adverse Event Reporting System (VAERS), 2009-2015. Vaccine. 2018;36(13):1781-8. https://doi.org/10.1016/j. vaccine.2018.02.034 PMID: 29477308

45. Neha R, Subeesh V, Beulah E, Gouri N, Maheswari E. Postlicensure surveillance of human papillomavirus vaccine using the Vaccine Adverse Event Reporting System, 2006-2017. Perspect Clin Res. 2020;11(1):24-30. https://doi.org/10.4103/ picr.PICR_140_18 PMID: 32154146 
46. Verstraeten T, Descamps D, David MP, Zahaf T, Hardt K, Izurieta $P$, et al. Analysis of adverse events of potential autoimmune aetiology in a large integrated safety database of ASo4 adjuvanted vaccines. Vaccine. 2008;26(51):6630-8. https:// doi.org/10.1016/j.vaccine.2008.09.049 PMID: 18845199

47. Shimabukuro TT, Nguyen M, Martin D, DeStefano F. Safety monitoring in the vaccine adverse event reporting system (VAERS). Vaccine. 2015;33(36):4398-405. https://doi. org/10.1016/j.vaccine.2015.07.035 PMID: 26209838

48. Baggs J, Gee J, Lewis E, Fowler G, Benson P, Lieu T, et al. The Vaccine Safety Datalink: a model for monitoring immunization safety. Pediatrics. 2011;127(Suppl 1):S45-53. https://doi. org/10.1542/peds.2010-1722H PMID: 21502240

49. Mouchet J, Salvo F, Raschi E, Poluzzi E, Antonazzo IC, De Ponti $F$, et al. Human papillomavirus vaccine and demyelinating diseases-A systematic review and meta-analysis. Pharmacol Res. 2018;132:108-18. https://doi.org/10.1016/j. phrs.2018.04.007 PMID: 29665426

50. Meggiolaro A, Migliara G, La Torre G. Association between Human Papilloma Virus (HPV) vaccination and risk of Multiple Sclerosis: A systematic review. Hum Vaccin Immunother. 2018;14(5):1266-74. https://doi.org/10.1080/21645515.2017.14 23155 PMID: 29333935

51. Genovese C, LA Fauci V, Squeri A, Trimarchi G, Squeri R. HPV vaccine and autoimmune diseases: systematic review and meta-analysis of the literature. J Prev Med Hyg. 2018;59(3):E194-9. PMID: 30397675

52. Koch JHT, von Kries R, Wichmann 0 . The risk of intussusception after rotavirus vaccination - a systematic literature review and meta-analysis. Dtsch Arztebl. 2017;114(15):255-62.

53. Ammon A, Prats Monné X. Vaccines, trust and European public health. Euro Surveill. 2018;23(17). https://doi. org/10.2807/1560-7917.ES.2018.23.17.18-00210 PMID: 29717694

54. European Centre for Disease Prevention and Control (ECDC). Let's talk about hesitancy. Stockholm: ECDC; 2016. Available from: https://www.ecdc.europa.eu/sites/default/files/media/ en/publications/Publications/lets-talk-about-hesitancyvaccination-guide.pdf

\section{License, supplementary material and copyright}

This is an open-access article distributed under the terms of the Creative Commons Attribution (CC BY 4.0) Licence. You may share and adapt the material, but must give appropriate credit to the source, provide a link to the licence and indicate if changes were made.

Any supplementary material referenced in the article can be found in the online version.

This article is copyright of the authors or their affiliated institutions, 2022. 
